Clinical Image

\section{Branchio Oculo Facial Syndrome}

\section{Maha Oudrhiri*, Toualouth L, Houda Oubejja, Fouad Ettayebi and Hicham Zerhouni \\ Department of Pediatric Surgical Emergencies of Rabat Children's Hospital, Faculty of Medicine and Pharmacy, Mohamed V University, Rabat, Morocco}

A 3-month-old girl presented to the surgical consultation room with bilateral cleft lip incomplete. A girl weighing $4205 \mathrm{~g}$, was born at term after an uneventful pregnancy with a birth weight of $2500 \mathrm{~g}$. There was no family history. On examination, a congenital, linear, erythematous cutaneous anomaly on the left side of her neck was highlighted with ocular anomalies (strabismus and the eyes are widely spaced) and a broad nose with a flattened tip. The examination of the other systems was unremarkable. In front of the association of these different anomalies BOFS was suspected but molecular diagnosis has not been made. The child benefited surgery to correct cleft lip with tennisson procedure with a good postoperative result.

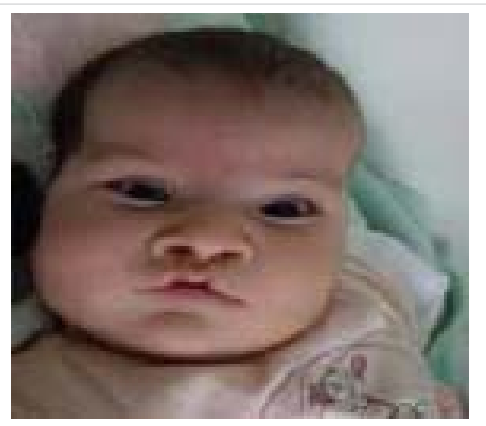

Figure 1: Showing bilateral cleft lip incomplete with strabismus.

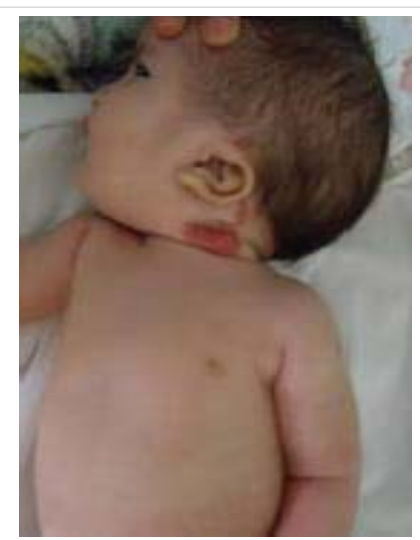

Figure 1: Linear erythematous cutaneous anomaly on the left side of the neck.

\section{More Information}

*Address for Correspondence: Dr. Maha Oudrhiri, Department of Pediatric Surgical Emergencies of Rabat Children's Hospital, Faculty of Medicine and Pharmacy, Mohamed V University, S12A11 Hay Riad Rabat, Morocco, Tel: +212661654515;

Email: oudrhiri.md.phd@gmail.com; maha.oudrhiri@gmail.com

Submitted: 27 November 2019 Approved: 28 November 2019 Published: 29 November 2019

How to cite this article: Oudrhiri M, Toualouth $\mathrm{L}$, Oubejja H, Ettayebi F, Zerhouni H. Branchio Oculo Facial Syndrome. J Adv Pediatr Child Health. 2019; 2: 020-020.

DOI: dx.doi.org/10.29328/journal.japch.1001007 Copyright: (c) 2019 Oudrhiri M, et al. This is an open access article distributed under the Creative Commons Attribution License, which permits unrestricted use, distribution, and reproduction in any medium, provided the original work is properly cited.

W) Check for updates 